\title{
Anancy y el tigre en la literatura oral afrodescendiente
}

\author{
Anancy and the Tiger in Afro-descendants Oral Literature
}

Anancy e o tigre na literatura oral afrodescendente

\section{Quince Duncan}

UNIVERSIDAD NACIONAL DE COSTA RICA (UNA), COSTA RICA

Profesor Jubilado de la Universidad Nacional de Costa Rica (UNA).

Doctor Honoris Causa, St. Olaf College, Nortfield, Minessotta,

Estados Unidos. Premio Editorial Costa Rica, 1978 y Premio Nacional

de Novela Aquileo J. Echeverría, 1979. Autor de más de 35 libros

de historia, crítica literaria, asuntos étnicos, manuales educativos y

textos de ficción. Correo electrónico: quinceduncan@gmail.com

Artículo de reflexión

Documento accesible en línea desde la siguiente dirección: http://revistas.javeriana.edu.co

doi: 10.11144/Javeriana.cl19-38.atlo 


\section{Resumen}

El artículo plantea el origen de la figura de Anansi y algunas funciones que cumple dentro de la literatura oral de los afrodescendientes, tanto míticas como ideológicas, ilustrando con ejemplos de África, el Pacífico Colombiano y Centroamérica, a lo largo del proceso de secuestro, esclavización y lucha por la libertad.

Palabras clave: literatura afrodescendiente; literatura oral; Anansi; Hermano Araña; Araña Nancy

\section{Abstract}

The article discusses the origin of the Anansi figure, and some functions that it fulfills within the oral literature of people of African descent, mythical and ideological, illustrating with examples taken from the Colombian Pacific, Africa and Central America; throughout the process of abduction, enslavement and struggle for freedom.

Keywords: Afro-descendant literature; oral literature; Anasi; Brother Spider; Anancy the Spider

\section{Resumo}

$\mathrm{O}$ artigo coloca a origem da figura de Anansi e algumas funções que tem dentro da literatura oral dos afrodescendentes, tanto míticas quanto ideológicas, ilustrando com exemplos da África, o Pacífico colombiano e Centro América, ao longo do processo de sequestro, escravização e luta pela liberdade.

Palavras-chave: literatura afrodescendente; literatura oral; Anansi; Irmão Aranha, Aranha Nancy

RECIBIDO: 22 DE JULIO DE 2014. ACEPTADO: 1 DE SEPTIEMBRE DE 2014. DISPONIBLE EN LÍNEA: 01 DE JULIO DE 2015

\section{Cómo citar este artículo:}

Duncan, Quince. "Anancy y el tigre en la literatura oral afrodescendiente". Cuadernos de Literatura 19.38 (2015): 65-78. http://dx.doi.org/10.11144/Javeriana.cl19-38.atlo 


\section{Consideraciones teóricas iniciales}

Toda sociedad y todo individuo es capaz de crear y consumir literatura. Por derivación, toda obra literaria se crea desde un punto de vista. Sin embargo, no hemos de inferir a partir del anterior aserto, que la obra responda solo a lo que de individual tiene el autor. No hay duda de que sus experiencias estarán presentes pero a la vez, las obras literarias -sean orales o escritas- se construyen a partir de la relación particular que ese autor establece con la naturaleza y con la sociedad. Se verá en la literatura la particular percepción del paisaje, retrospectivamente y en tiempo actual. La obra literaria ofrece también una interpretación de las relaciones sociales, de los procesos sociales históricos, de la memoria ancestral, de las tradiciones. La literatura ofrece al final de cuentas, propuestas de visiones de mundo a la colectividad; visión que, dicho sea al vuelo, puede contribuir a destacar elementos del medio, a la formación de la consciencia de grupo, a la construcción de una meta-conciencia humana.

Sobre el enunciado dicho, se concluye que la literatura en su conjunto es una propuesta que, sin ser epifenómeno simple del pensamiento colectivo, se articula a partir de él. Sin embargo, hay que cuidarse de no caer en idealismos. La función de la literatura no es la reproducción o la representación fiel de la realidad. Literatura es también imaginación, es ficción. Es expresión artística que postula una realidad imaginada. Es entonces, en última instancia, el discurso de lo imaginario.

En ninguna otra dimensión de la literatura es más palpable la relación entre el autor, el cuenta cuentos, que en la literatura oral. Si bien todos los autores están inmersos en una sociedad y no se escapan por tanto de la programación social, lo cierto es que el cuenta cuentos se instala de frente a su audiencia. Puede observar de primera mano las dinámicas de clase social, nacionalidad, etnia, raza, género, cultura, política, religión y filosofía..., en fin, va a reconstruir o reinventar la realidad imaginaria, "en vivo y en directo".

\section{El tema}

El presente estudio aborda la literatura oral desde el punto de vista sistémico, en concreto, una manifestación de la literatura oral de la población afrodescendiente, los cuentos de Anansi fenómeno que se acentúa a lo largo y ancho de lo que se conoce como el Gran Caribe, región cultural que se extiende desde New Orleans en el norte hasta las Guyanas en el Sur y en el Pacífico colombiano.

El personaje Anansi surge en la cultura akan del África; reconstruida en parte, pero elaborada a partir de las nuevas experiencias, forma una porción inseparable del acervo cultural de los afrodescendientes. Anansi es un personaje 
que en sus orígenes alcanza ropaje de divinidad. En efecto, la deidad de la cultura akan estaba compuesta por el dios Nyame, dios único expresado en tres personas: Odomankoma que es Dios infinito, Kuaku Anansi, el que teje el universo y Asase Ya, la expresión femenina de Dios, la que da formato a la tierra. Aunque hay varias versiones de esta tradición oral, en algunos de los cuales Anansi habitaba la tierra y visitó el cielo, lo cierto es que todos coinciden en que se apropia de los cuentos, sea o no con el permiso de Nyame y se los trae para la tierra para esparcirlo entre los humanos.

En algunas de las versiones, eso le valió su posición como parte de trinidad, siendo sustituido por el Camaleón. Pero su función en la tierra es contar los grandes mitos de la creación y las relaciones sociales, dando siempre una enseñanza a manera de moraleja. Entre los akan, contar los relatos era una cuestión que se abordaba con la mayor seriedad, pues la palabra podía tener efectos mágicos. Se reconocía que Nyame Dios, era el autor de todas las historias, y que los tenía bajo su custodia. Los cuentos eran verdaderas entelequias vivientes, con una existencia propia. En nuestra teoría literaria actual, diríamos que los cuentos de Anansi tenían una gran autonomía relativa, incluso frente a los mismos contadores, que solo eran transmisores. Estaba claramente establecido así, que los relatos no eran de autoría humana sino creaciones del mismo Dios del Cielo y por tanto, estaban en la dimensión de lo sagrado.

No en vano en la cultura originaria y en respeto a lo dicho, los cuentos se contaban al amparo de la oscuridad. Pero además, el contador de estas historias se cuidaba de dar una disculpa al repetir las historias, agregando y poniendo elementos para hacerla más interesante con unas palabras rituales. Aclaraba que su intención no era decir lo que iba a decir y que en todo caso, él no era el autor. Era una declaración necesaria para proteger al narrador por el atrevimiento de tomar y modificar la historia original.

Vale la pena señalar que los contadores de cuentos africanos eran verdaderos juglares con una gran licencia socio-política y religiosa. El contador podía tomarse la libertad de hablar de aspectos de la vida que eran tabú en la comunidad. Estaba facultado para cuestionar ciertas creencias religiosas; podía criticar impunemente las decisiones del rey y su familia; podía discutir los temas cotidianos, juzgar y condenar a los infractores, siempre bajo la protección de las historias mismas que, siendo creadas por el mismo Dios del Cielo, no eran susceptibles de censura política, religiosa o social. Se podía denunciar por ejemplo, la corrupción de un dignatario religioso y la crueldad de un jefe tribal o rey sin exponerse a represalias. Sobre todo si el contador anteponía la fórmula ritual de que realmente no hacía suya ninguna de sus historias, ni tenía la intención de causar daño alguno. 
Anansi cuenta los grandes mitos de los pueblos, dando sentido a ciertas realidades políticas y religiosas, pero también llenando los vacíos míticos necesarios en la formación de los niños. En ese sentido, hay cuentos que explican cosas como por qué el tigre tiene manchas, por qué las arañas tienen ocho patas, o por qué Dios, que al principio habitaba entre los humanos, finalmente decidió retirarse para habitar en los cielos.

Así, vemos el caso de esta astuta araña en África, robando agua del estanque de los "diablos". Es un cuento reciente sin duda, dado el uso de la palabra diablo que denota la influencia cristiana. Según el relato, ante una gran sequía, solamente había agua en la aldea de los diablos. Entonces Anansi, valiéndose de su astucia, fue a la aldea con dos calabazas con dos pequeños agujeros, amarradas a su cintura, pidió y obtuvo permiso para bañarse, eso sí con la condición de que no se llevara ni una sola gota de agua. Por supuesto, que al terminar de bañarse y salir del agua las calabazas iban llenas. La hiena, cuando se enteró de que la araña y su familia tenían agua, exigió bajo la amenaza de amputarle el dedo que le revelara el secreto, ante cuya presión accedió Anansi. Pero la hiena con un exceso de confianza en su fuerza, en vez de calabazas llevó un par de cántaros. Desde luego que no pudo salir del estanque con el peso de su carga, por lo cual, los diablos descubrieron su ardid y le dieron una tremenda paliza:

Se precipitaron sobre ella con sus nudosas estacas. La hiena reunió las pocas fuerzas que le quedaban, dio un salto y corrió a la jungla, de donde el miedo no la dejó salir otra vez. Por eso lleva todavía allí una vida salvaje, en lugar de vivir, como antes, en una bonita casa. Y por eso suelen decir los viejos cuando algún joven presume de astuto: no basta tener astucia; es necesario saber administrarla. (Religiosas Misioneras Combonianas, s.f.:127-129)

Con los africanos secuestrados de sus territorios, trasladados a través del Atlántico para ser esclavizados en el Gran Caribe, vienen los cuentos de Anansi.

\section{Evolución en el Caribe}

El secuestro, captura, transacción y los otros múltiples métodos de esclavización impuestos sobre los pueblos africanos, implicó la migración de enormes contingentes de africanos al Caribe insular y continental. Se crearon complejos mestizajes intra-africanos, mediante los cuales los diversos grupos culturales fueron despojados de sus filiaciones étnicas originarias, para crear una complejidad cultural nueva: la población negra.

Los inmigrantes forzosos, dejaron de ser Fanti, Mandinga o Brong, para ser simplemente negros. Un fuerte input en la mezcla caribeña es el de los ashanti, 
que llegan al Caribe en una época tardía. Constituyen un pueblo que había logrado mantener su independencia hasta bien entrado el Siglo XIX. De hecho, tras varias guerras con la Gran Bretaña la Federación Ashanti fue derrotada en 1874 mediante una combinación de poderío militar británico e intriga diplomática, cuando los ingleses finalmente lograron saquear Kumasi, su capital. Los ashanti se rebelaron en 1901 pero perdieron la guerra y fueron reducidos a un protectorado y después a una colonia.

En América el personaje evolucionó, adaptando su nombre al idioma local. Anansi es conocido en el Gran Caribe como Hermano Araña, Breda Nansi, Anancy, Ananse, Anance, Ananci, Anansy, Aunt Nancy, "Ti Malice" o simplemente "Nansi" y su presencia es fuerte sobre todo en las tradiciones del Caribe insular y del Caribe Continental centroamericano, pero también en el pacífico colombiano.

\section{Los cuentos}

Los cuentos de Anansi contienen personajes que son personificaciones de animales. Se escogen según sus semejanzas con la conducta humana. Por ejemplo, el Hermano Tigre suele ser valiente y violento pero un poco torpe, mientras que la Araña es físicamente débil, pero bribona y taimada. También hay personajes humanos, con nombres inventados que en ningún caso deberían coincidir con los nombres de personajes reales.

Si en África sus cuentos explicaban los grandes mitos del pueblo y facilitaban la crítica social y religiosa, en el Caribe pasa a ser el transmisor de la ideología de sobrevivencia. Es la astucia más que la inteligencia lo que va a permitir la sobrevivencia. En efecto, los cuentos en el Caribe insular o continental, privilegian el triunfo de un personaje más bien débil, incapaz de enfrentar por la fuerza a los poderosos animales que lo rodean. No es rival para el tigre o para el lagarto desde el punto de vista de su capacidad física. Entonces recurre a la astucia. Es mediante sus trucos que logra vencer a los poderosos. De hecho, el 'buen esclavo' tenía una expectativa de vida de un máximo de siete años a partir del momento en que fuese reducido a la esclavitud.

$\mathrm{Al}$ igual que en África, el contador recurre al ritual para justificar su uso del contenido subversivo y desafiante de sus relatos. En el caso de Jamaica, antes de contar sus relatos, invoca a Jack Mandora, que en la tradición caribeña es el guardián de las puertas del Cielo, para aclararle que "me no choose none", vale decir, no estoy optando por ninguno, no me estoy apropiando de ninguna de las historias, no estoy haciendo mía la historia ni tengo la intención de hacer ningún daño a nadie con ese cuento. Contarlo con esa advertencia liberaba al narrador de que el acto narrativo fuese un acto pecaminoso del cual el responsable tendría 
eventualmente que responder. Los relatos transcritos dan una clara muestra de continuidad y diversidad.

\section{EJeMPLo 1. Pacífico colombiano:}

"Hermano tigre, hermano Anancy y el pescado frito"

Érase una vez cuando el tiempo era tiempo, el Hermano Anancy fue a la orilla del mar para ver si su nasa había atrapado algún pez grande o por lo menos algunos pequeños para poder llevar a su casa. Cuando los terminó de limpiar y colgarlos de una cuerda para poderlos llevar mejor y apenas había emprendido el viaje hacia su casa, vio una luz que se le acercaba y pensó: "Allí vienen mis hijos a visitarme”, y se alegró mucho, pero ¡oh, sorpresa! ¿Quién creen que era? Ni más ni menos que el Hermano Tigre.

Anancy estaba tan asustado que no sabía qué hacer, lo único que pensó fue: "Debo ser muy amable con Tigre, y así salvarme el pellejo". Entonces puso una sonrisa y dijo: "Hola Hermano, qué bueno verte. Te traje con el pensamiento. Me decía a mí mismo: Tengo mis días de no ver a Tigre, sería muy bueno ir a hacerle una visita y llevarle unos pececitos. Pero ya que estás aquí, creo que lo mejor sería de una vez". Cuando Tigre oyó eso, pensó: "No, mejor que yo deje que me lleve a su casa, así puedo comerme a su familia". Entonces dijo: "Hace tiempo que no veo tu linda familia, más bien voy contigo y los como allá, si no te importa". Anancy no era tonto y sabía que Tigre traía algo en mente, pero como no tenía salida contestó rápidamente: "No faltaba más, acompáñame por favor". Cuando llegaron a la casa de Anancy, su esposa se sorprendió: ¿Pero por qué Anancy trajo a Tigre aquí? Pero pensó: "Él tendrá algún plan en mente". Así que se puso a fritar los pescados, preparar jugo, y tenía pan caliente, y se sentaron todos a comer.

Durante la comida Tigre solo pensaba cómo iba a sorprender a la familia de Anancy y comerlos. Pero lo que no sabía Tigre es que ya Anancy tenía en mente un plan. Había ido a donde sus hijos y les había dicho: "Métanse en el palo de calabaza". Así se fueron levantando de la mesa uno por uno y finalmente la esposa. Fue cuando Anancy dijo: "Tigre, excúsame por un momento, debo ir al baño", y también se trepó en el árbol de calabaza. Tigre esperó por un momento, pero cuando se dio cuenta del truco se puso loco de la rabia. Miró al árbol y dijo: "No me moveré de aquí hasta no vengarme de ti". Cuando Anancy vio que era en serio, se dio cuenta que sus hijos y su esposa estaban cansados y a punto de caer, entonces dijo: "Tigre, ya sé que tenemos que caer en tus manos, pero, ¿por qué vas a perder tanta carne y tanta grasa cuando caigamos al piso? ¿ ¿Ves ese tinaco que está allá? Cógelo y ponlo debajo del 
árbol. Así cuando caigamos no pierdes nada". Y Tigre se emocionó y fue por el tinaco y lo colocó debajo del árbol. Entonces le dice Anancy: "Llénalo de ceniza". Y Tigre fue por la ceniza y lo llenó. Luego le dice Anancy: "Coloca tu cuello para hacer el ensayo". Y así lo hizo Tigre. Fue cuando Anancy agarró una calabaza y se la tiró con toda su fuerza y salió Tigre lastimado y corriendo. (Colombia Aprende)

El relato nos deja ver buena parte de la mentalidad de los afrodescendientes, oprimidos, en cautiverio. El mensaje es claro: el poderoso tigre no logra su propósito, no porque le faltaran fuerzas. De hecho, al igual que la hiena en el cuento africano, es fuerte y poderoso. Lo que lo vence es la astucia de la araña. $E l$ tigre sale lastimado y huyendo.

\section{EJEMPLo 2. Centro América}

La dependencia en la astucia y no en la fuerza, es muy evidente en todos los relatos en que se enfrentan la araña y el tigre. Por ejemplo, en el caso de un cuento recogido entre la población garífuna de Honduras, el tigre, luego de pasar por el mismo transe que se cuenta a continuación, sufre castración y posteriormente su muerte, siempre vencido por la astucia de la araña (Gallardo 68-73).

"Caballo de Trote"

Como que al Hermano Araña le gustaban varias de las muchachas del pueblo. Pero, también, como que el Hermano Tigre era el popular. Y es que su fama de don Juan enloquecía a más de una.

Al Hermano Araña no le podía gustar eso. Era duro el hecho de que con cuanta muchacha hablaba, le saliera con el mismo nombre. De ahí nació cierta rivalidad entre ambos.

Pero al Tigre poco le preocupaban los berrinches de la Araña. Al fin y al cabo él tenía su mechoncito blanco en la melena, y eso era lo que más cautivaba el corazón de las damitas.

Muchas veces el Hermano Araña trató de cortarle el mechón, mientras el Tigre dormía. Pero éste siempre accionaba a tiempo y una vez estuvo a punto de matar a su rival.

Esto último convenció al Hermano Araña acerca de la torpeza de ser temerario. Y no fue demasiado costoso decidirse a usar su conocida astucia. Tal fue el comienzo del descrédito sistemático del Hermano Tigre. Y al poco tiempo corría de boca en boca la noticia, de que el tal Hermano Tigre, con todas sus pretensiones, no era más que el caballo de trote del Hermano Araña. Ya los niños se atrevían a cantarle por las esquinas: 
"Hermano Tigre se te acabó la maña

Desde que te Ponta el Hermano Araña".

Ante esto, el Hermano Tigre reaccionó con violencia y fue a la casa del Hermano Araña para reclamarle en el terreno de los hombres. Pero lo halló gravemente enfermo, revolcándose y quejándose de un fuerte dolor de estómago. -A mí qué me importa su dolor. Me tiene que probar eso que dijo. Si no puede, tiene que ir al pueblo ahora mismo y negarlo en presencia de todos -Pero Hermano Tigre, no sea cruel. Véame cómo estoy. Además sabe lo mucho que yo le aprecio. Usted sabe que yo no sería capaz de decir tal cosa.

-Usted lo dijo: tiene que ir a negarlo públicamente.

-Con gusto lo haría, pero estoy mal, muy mal...

-Yo no puedo esperar a que usted se componga. A lo mejor se muere.

-Pero es que -el rostro enojado del Hermano Tigre producía escalofríos y el Hermano Araña, al convulsionarse, ablandó un tanto la ira del Tigre.

-Bueno... está bien. Si usted me lleva, con mucho gusto voy a la plaza ahora mismo.

Así convinieron. Pero al subir el Hermano Araña por un costado a los lomos del Tigre, fingió caer del otro lado. El Tigre consintió dejarse poner silla y freno, con tal de que no se fuera a caer de camino.

Pero el Hermano Araña se quejaba de las moscas, por lo cual el Tigre le dio un chilillo para que las espantara.

Un poco antes de entrar al pueblo, se compuso milagrosamente el Hermano Araña y tomando las riendas severamente empezó a castigar los lomos del Hermano Tigre, obligándole a trotar con evidente buen estilo.

Y llamando a voz en cuello a las pretendidas del Hermano Araña, lo paseó por todo el pueblo entre la algarabía de los niños y la admiración de las jovencitas más osadas.

Y quedó desde entonces demostrado que el Hermano Tigre no es sino el caballo de trote del Hermano Araña.

Donde quiera que vea un tigre trotando, fíjese en su lomo. Allí verá al Hermano Araña muerto de risa.

(Duncan ctd en Chang et al., 168-172)

\section{Nuevas versiones}

En la actualidad hay autores que vienen construyendo su ficción a partir de Anansi. Vale decir, ya no se trata de reproducir las historias antiguas con las adaptaciones y modificaciones que se han realizado tradicionalmente, sino de una búsqueda de nuevas formas de expresión de Anansi, entendida como una 
filosofía de sobrevivencia y a la vez, una visión afro-céntrica del mundo. Tal fue el ejemplo de Andrew Salkey (1928 - 1995) un escritor del Gran Caribe, nacido en Panamá de padres jamaicano y haitiano, criado en Jamaica y radicado a la hora de su muerte en los Estados Unidos. Su libro Anancy's Score (1973) es una colección pionera de cuentos de Anansi que tienen la virtud de partir del personaje en cuestión, respetando su particular manera de enfrentar la realidad, pero al mismo tiempo, echando a volar su imaginación en un amalgama del Anansi africano, con el folklore tradicional caribeño y su propia creatividad literaria.

Esa recreación a partir de Anansi, incluye obras de mayor alcance, como en el caso de la novela Los hijos de Anansi del escritor británico Neil Gaiman. En 2005 esta novela alcanzó el primer lugar en la lista de bestsellers del New York Times. En la trama de la novela, resulta que Anansi tiene dos hijos, prácticamente gemelos. En el transcurrir de la novela se descubren: un hermano bastante ingenuo y el otro, un Anansi a cuarta potencia, capaz de mimetizarse y asumir así oficio de camaleón. Las aventuras de estos hijos de Anansi, pasan del Gran Caribe (La Florida) a Londres y viceversa, burlando a la muerte, trastrocando el orden del universo mismo.

Tal es el caso de Los Cuentos de fack Mantorra de Duncan. Acá vemos a Anansi en la Ciudad.

Anansi luchando por su vida, se salvó de ahogarse del río milagrosamente porque nunca aprendió a nadar. (Los animales de la selva, donde era rey, cansado de sus fechorías se levantaron contra él y lo hubieran matado si no huye). Estuvo mucho rato en la ribera, botando toda el agua que había tragado, que era casi la mitad del río. Cuando finalmente se recuperó decidió pensar seriamente en lo que iba a hacer de ahí en adelante.

En realidad, tenía muchas razones para pensar. Se dio cuenta que había perdido su reino por mañoso. Jack Mantorra dice que no hay que olvidar que Anansi fue rey en Tuculandia. Y ahora, ya no podía seguir viviendo en la selva por la misma razón: más de una fechoría les había hecho a la mayor parte de los animales.

Decidió mejor comenzar a caminar siguiendo el camino. Andando y andando llegó a la línea del tren, en el mismo momento en que iba saliendo hacia la gran ciudad. Se coló en uno de los vagones, y escondiéndose entre la mercadería que llevaban logró viajar sin tener que pagar su boleto.

Así llegó a la ciudad. Anansi, cuando ya comenzó a entender las cosas de la ciudad, se dio cuenta que en el barrio en el que vivía, o mejor dicho, en el barrio en que se escondía, mandaba el Hermano Gato. Este tenía una fábrica de hamburguesas de diferentes tipos de carnes. Un rótulo inmenso a la entrada 
del negocio decía que vendía carne para hamburguesas. Entre las variedades estaban las siguientes:

"perro burguesas"

"conejo burguesas"

"caballo burguesas"

"pollo burguesas"

"lagarto burguesas"

... y así por el estilo.

Una noche, cuando ya no aguantaba el hambre, y estaba cansado de meterse a los restaurantes a comer lo que la gente dejaba, se consiguió una escalera para saltar sobre el muro del almacén del Hermano Gato para robarse una cena. Logró llegar a la parte alta del muro, pero no contaba con que el Hermano Gato había instalado sobre la tapia un sistema de protección eléctrica que daba una descarga terrible a los que se subieran allí.

Pues bien, cuando Anansi sintió aquella descarga, se soltó del muro y cayó de cuerpo entero. Quedó un buen rato sin poderse mover. Pero al fin, marcó el sitio en que había caído con unas ramitas, escondió la escalera y se puso a pensar de qué manera podría sacarle provecho a la trampa que había puesto el Hermano Gato.

Apenas tuvo el plan pensado, se presentó a la oficina del Hermano Gato y le ofreció suministrarle carne para sus hamburguesas. Le explicó que él conocía muy bien la selva, que todos los animales lo conocían muy bien, y que no sería difícil cazarlos, si contara con el apoyo de Hamburgesas Gatunas, la empresa de la que era dueño el Hermano Gato.

A los días comenzó a cambiar la situación de Anansi. Jack Mantorra lo vio comprar un jeep de lujo. Dice que vestía zapatos blancos en sus cuatro patas, llevaba un pastón negro en una de sus cuatro manos, un par de guantes en otras dos y un puro en la otra. Mandó a pintar un rótulo en el jeep que decía, "Anansi Tours", y debajo en letras pequeñas: viajes de turismo. Eso fue el miércoles. Y ya el viernes, Jack lo vio irse por el caminito de la selva en su jeep de lujo...

Iba de pueblo en pueblo, vendiendo a los animales excursiones por la ciudad. Era un buen negocio y al poco tiempo Anansi tenía una gran casa con piscina, un carro de lujo con teléfono portátil, un yate en Limón, una hacienda en Guanacaste, una casa en Miami y un equipo de fútbol con su nombre: Deportivo Anansi Boys.

Todo iba bien, muy bien. Solo que la Hermana Lagarto, a quien Anansi en una ocasión le había comido sus huevos, le puso precio a su cabeza. Ella esta- 
ba dispuesta a pagar un millón de monedas reales para capturarlo y castigarlo por lo que hizo con sus hijos. Pero era muy difícil capturarlo, porque con todo el dinero que tenía ahora, Anansi no aparecía en público en ninguna parte, pues se había comprado un helicóptero y nadie lo lograba detener.

Pero Tucumá, el famoso Tucumá, sobrino de Anansi, que ahora también vivía en la ciudad, oyó el cuento y quiso averiguar por qué le iba tan bien a Anansi y además cuál era el negocio que tenía con el Hermano Gato, que también tenía fama de tramposo. Así que se propuso investigar el caso y además, en caso de que lograra capturar a Anansi, prometió donar su dinero al hospicio de huérfanos porque él ya tenía suficiente dinero para vivir bien.

Tucumá se fue al campo a preguntar en los pueblitos de la selva por las fechorías de Anansi. Todos le decían que Anansi ahora era un gran señor, que se había compuesto totalmente, que ya no robaba huevos de lagarto, que andaba de zapatos de charol y valija ejecutiva y que ahora era una persona de bien, incapaz de hacer nada malo. Tucumá sin embargo, no se quiso tragar el cuento, pero eso era lo que decían todos, de modo que no había por donde hacer nada. Y estaba por abandonar sus investigaciones cuando comenzó a notar algo extraño: de cada diez animales que iban a la ciudad en la excusión de Anansi, tres no volvían nunca al pueblo.

Tucumá preguntó a todo el mundo cómo explicaba eso y le respondían que es que se quedaban trabajando que el mismo Anansi, que les buscaba trabajo con su amigo el Hermano Gato. Todo eso intrigó a Tucumá, quien entonces se disfrazó de Tiburón y compró un boleto en la excursión de Anansi.

Pues bien, dice Jack Mantorra que al principio todo iba muy bien. Los guías enseñaban todas las cosas bellas que tenía la ciudad a los excursionistas; los monumentos, las fuentes, las luces, el Museo de Oro, el Museo de Arte, el Museo Nacional, El Parque Nacional de Diversiones, el Parque Metropolitano de la Sabana, el Parque González Víquez, en fin, muchas otras cosas bonitas. Pero por la tarde, se presentó Anansi en persona para invitar a los que querían quedarse trabajando en la ciudad a una reunión. Se ofrecieron cuatro animalitos y Anansi se los llevó en su auto de lujo.

Tucumá se disfrazó de ratón para seguirlos por los caños y las alcantarillas y de ave nocturno para controlarlos desde el aire. Y fue así como descubrió el truco de Anansi. Resulta que los llevaba jadivinen donde! Pues ni más ni menos que al muro del Hermano Gato, donde el mismo Anansi había recibido la descarga eléctrica y había caído. Los llevaba allí de uno en uno y los invitaba a hacer "la prueba del muro" por medio de la escalera, pero claro, los pobres no sabían nada de la descarga eléctrica. 
Los animales subían confiados, pero al llegar arriba ¡pum! ... los sorprendía aquel golpe de electricidad; pegaban un rebuzno, un relincho, un cuac o lo que fuera y se caían al suelo, donde el maloso de Anansi tenía una trampa para animales. Como quedaban turuletos, allí mismo los recogía y se los llevaba al almacén del Hermano Gato y los vendía, este para pato burguesas, este otro para burro burguesas y todavía este otro para tijo burguesas.

¡Así que ese era el negocio de Anansi!

Era mejor negocio la venta de los animales que las excursiones, las que, en realidad, solo servían de anzuelo para atraer a sus futuras víctimas. En vez de dedicarse al trabajo honrado de organizar paseos, quiso buscar el dinero fácil, vendiendo a sus compañeros animales.

Pues bien, Tucumá habló con los animales de la selva. Les hizo ver lo que estaba haciendo este bandido de Anansi. Y fue así como entre todos celebraron una gran reunión, para ponerse de acuerdo y librarse de una vez por todo del tal tramposo.

Cuenta Jack Mantorra que él estuvo en la reunión. Dice que todo el mundo estaba allí y que todos tenían alguna queja contra Anansi. Decidieron venirse a la ciudad y obligar a Anansi a caer en su propia trampa y eso fue lo que hicieron.

Con mucha maña lo invitaron a una fiesta con todos los animales. Anansi pensó que era su gran día, porque allí iba a conocer a muchos animalitos tontitos que querían trabajar en la ciudad para seguirlos engañando. Lo que menos se imaginaba es que los animalitos no eran tontos: lo que les había estado pasando era por confiados nada más. De modo que cuando Anansi vino a la fiesta lo capturaron y lo llevaron al muro del Hermano Gato y lo obligaron a subir por la escalera hasta la parte de arriba.

Por supuesto que Anansi sabía lo que iba a ocurrir. Así que, un poco antes de llegar a la parte superior se hizo araña y lanzó su tela y por eso, cuando recibió la descarga eléctrica no cayó al suelo, sino que su telaraña lo sostuvo. Pero tuvo que quedarse a vivir en los techos y en los muros.

Dice Jack Mantorra que si no creen lo que cuenta, que se fijen en la parte de arriba de los muros y en las esquinas de los cielorrasos, van a ver allí a Anansi, convertido en araña, sin poder bajar al suelo por miedo de ser atrapado. Pero según Jack es cuestión de tiempo, pues como sucede con todos los mañosos y tramposos, más tarde o más temprano caen en su propia trampa.

(Duncan, Los cuentos de fack... 1977, 28-31) 


\section{A manera de reflexión final}

Anansi acompaña a los africanos desde sus territorios natales hacia las Américas. Se afinca en el contexto cultural del gran Caribe, aunque también se manifiesta en el Pacífico y ahora en Europa. Sus historias fueron transmitidas de una generación a otra y se mantuvieron en esencia, a pesar de que cada contador le agregaba su propio verbo y le restaba o sumaba significados específicos para mejorar su comunicación con su audiencia o para dar su mensaje. Igualmente, un mismo contador variaba el contenido según las circunstancias, pero manteniendo el mensaje.

Los cuentos de Anansi pueden ser divertidos, pero siempre aleccionadores, dejando incluso espacio para el comentario final del cuenta-cuentos o para la opinión del grupo. Por otra parte, Anansi realiza una función central en la conservación y enriquecimiento de la memoria ancestral, permitiendo no solo su propia reproducción sino también la reinvención y actualización de los valores fundamentales de la cultura del pueblo afrodescendiente.

\section{Obras citadas}

Chang, Giselle et.al., comps. Cuentos tradicionales afrolimonenses.

San José: Editorial Costa Rica, 2006.

Colombia Aprende. "Hermano tigre, hermano Anancy y el pescado frito".

Literatura y Tradición Oral. Bogotá: Colombia Aprende. Disponible en

http://www.colombiaaprende.edu.co/html/etnias/1604/article-82872.html

Dittmann, Marcia y Lolia Pomare. Nacimiento, vida y muerte de un sanandresano. Bogotá: Ministerio de Cultura, 2000.

Duncan, Quince. Los cuentos del Hermano Araña. San José: Editorial Territorio, 1975.

-. Los cuentos de fack Mantorra. San José: Editorial Territorio, 1977.

Gaiman, Neil. Los hijos de Anansi. Barcelona: Rocabolsillo, 2008.

Gallardo, Mario. "La Araña y Tío Tigre". La danta que hizo dugú.

Honduras: Secretaría de Cultura, Artes y Deportes, 2007. 68-72.

Religiosas Misioneras Combonianas. "La Araña y la Hiena". Fábulas

Africanas. San José: Editorial Mundo Negro. s.f. 127-129.

Salkey, Andrew. Anancy's Score . Londres: Bogle-L'Ouverture Publications, 1973. 